Research Article

\title{
Brittle Characteristic and Microstructure of Sandstone under Freezing-Thawing Weathering
}

\author{
Songtao Yu, Junren Deng, Hongwei Deng $(D$, Feng Gao, and Jielin Li \\ School of Resources and Safety Engineering, Central South University, Changsha 410083, Hunan, China \\ Correspondence should be addressed to Hongwei Deng; denghw208@126.com
}

Received 9 June 2020; Revised 22 August 2020; Accepted 31 August 2020; Published 21 September 2020

Academic Editor: Yixian Wang

Copyright ( 2020 Songtao Yu et al. This is an open access article distributed under the Creative Commons Attribution License, which permits unrestricted use, distribution, and reproduction in any medium, provided the original work is properly cited.

\begin{abstract}
As an important property of rock material, brittleness plays a vital role in rock engineering. This paper raised the concept of elastic strain energy release rate and proposed an elastic strain energy release rate based brittleness index based on the most acceptable definition of brittleness. Mechanical and Nuclear Magnetic Resonance parameters of sandstone under various Freezing-Thawing (F-T) cycles are also acquired and analyzed. Then, the proposed brittleness index is used to compare with two recently proposed brittleness indices to verify its correctness and applicability. Finally, the brittleness index is applied to evaluate the brittle behavior of F-T cycles treated sandstone under uniaxial compression. The results show that elastic modulus, value of the postpeak modulus, and peak stress decrease with F-T cycles, and the porosity and microstructure develop with F-T cycles. The proposed brittleness index is highly related to F-T cycles, peak stress, porosity, and elastic modulus of sandstone that suffered recurrent F-T cycles. It declines exponentially with F-T cycles and porosity increase while growing exponentially with peak stress and elastic modulus increase.
\end{abstract}

\section{Introduction}

As a kind of geological weathering, Freezing-Thawing (F-T) cycles occur in many environments and usually cause negative effects in the real world. For example, F-T cycles are responsible for the degradation of the material of cultural/ historical buildings and monuments [1], instability of mine slope, the debasement of stability of road and road/railway tunnel [2], and the occurrence of rockfall [3]. With researches going deeper, a series of physical and mechanical parameters, that is, elastic modulus, porosity, and damage factor, were adopted to characterize damage of the materials while a proper index characterizing damage and failure behavior of the materials that subjected to F-T cycles is deficient.

Brittleness is an important mechanical parameter that has a strong influence on the deformation and failure process of rock and on rock mass response to mining activities and slope engineering. It characterizes the brittleness of rock, and it is also a complex property that is hard to be defined and calculated. Hucka and Das [4] proposed four definitions of brittleness and pointed out their deficiency. Meng et al. [5] pointed out the most acceptable and understandable definition of brittleness, which is material terminating by fracture only slightly beyond the yield stress. Due to the complexity of brittleness description, uniform definition of brittleness has not formed yet.

Among these years, many brittleness indices have been put forward. Coates and Parsons [6] quantified brittleness with the percentage of the reversible strain and proposed brittleness as the ratio of the reversible strain to the total strain at the failure point. Different from Coates who only used strain before the peak point to quantify brittleness, $\mathrm{He}$ et al. [7] and Dolmajid and Kaiser [8] took postpeak strain or plastic strain at which cohesive strength reduces to its residual value into account to describe brittleness. Andreev [9] believes that the rock brittleness has a linear relationship with the irreversible longitudinal strain, and the brittleness can be expressed as a value equaling one hundred times of longitudinal strain. Li et al. [10] divided brittleness into peak strain index and postpeak curve shape index and considered the effects of peak strain and peak stress reduction rate when 
describing brittleness. Many brittleness indices [4, 11] were proposed based on strength. Bishop [12] raised brittleness an index that is equal to the ratio of reduction of peak stress during the failure to the peak stress to represent the brittleness of the material. In order to assess the degree of rock brittleness, Meng [5] proposed a brittleness index to account for the strength loss and path of stress drop. Xia [13] described brittleness by two parameters, namely, the postpeak stress drop rate and the ratio of the elastic energy released during the failure to the total energy stored before the peak strength.

Energy evaluation in the complete stress-strain curve is a vital and effective perspective for brittleness description, and much work [14-18] has been done from this aspect. Hucka and Das [4] raised an energy-based index to measure the degree of brittleness of rock, which is the ratio of elastic strain energy to the total strain energy before peak stress. Munoz et al. [19] proposed three brittleness indices that described the relation of elastic energy, prepeak strain energy, and total fracture energy to quantify the brittleness. Tarasov and Potvin [20] took postpeak rupture energy, withdrawn elastic energy, and released elastic energy as variables and proposed a brittleness index. Zhang et al. [21] took the dissipation energy of the prepeak stage into account and came up with two indices of energy-based brittleness.

Although these indices have their characteristics, they also have some disadvantages. Those indices defined purely by strains have a fatal flaw that has not considered the effects of the postpeak characteristics on its brittleness. Most of the brittleness indices built based on stress did not consider the fracture mechanism of the rock. In terms of energy-based indices, Hucka and Das [4] completely neglected the postpeak characteristic of rock, which brings crucial defect to its correction when measuring the brittleness of rock. Munoz et al. $[19,20,22-24]$ did not consider the influence of stress drop path on brittleness measuring.

It is a consensus that the failure process of brittle material is fast in the time dimension while the failure process of ductile materials is relatively slow. Therefore, the postpeak failure rate of the material is a key parameter to describe the brittleness. Even though some scholars have considered the postpeak failure rate by introducing the stress drop rate or postpeak modulus into brittleness index, nevertheless, those indices neglected the influence of stress drop path. Additionally, estimating brittleness indices based on energy evolution is an effective and primary method at present. Though, there is no research that takes the rate of energy change during the failure process as an influencing factor to characterize the postpeak failure rate when describing the degree of brittleness.

As the brittleness of rock under F-T weathering plays a vital role in evaluating stability and failure modes of geotechnical engineering in cold regions, in this study, an energy-based brittleness index that considering the influence of the postpeak failure rate is proposed and verified by comparing it with the recently proposed brittleness indices. And the parameters related to brittleness of sandstone, mechanical parameters, and microstructure are also tested and analyzed. Finally, the brittleness index is applied to evaluating the brittleness of sandstones subjected to recurrent F-T cycles, and the brittleness and microstructure variation trend of sandstone with F-T cycles is revealed.

\section{Brittleness Index Establishment}

2.1. Establishment of Brittleness Index. Assessing the degree of brittleness of the materials should be based on the definition of brittleness. As mentioned above, even though the definition of brittleness has not been unified yet, the most acceptable and understandable definition of brittleness currently is that the material terminates by fracture only slightly beyond the yield stress. One important description of the definition indicates that the postpeak characteristics have a strong impact on the brittleness index. Put it more specifically, the length of the fracture stage directly relates to the degree of brittleness. Under the same condition, the shorter the length of the fracture stage, the more brittle the material.

Currently, measuring brittleness based on the stress drop rate and the energy evolution during loading are two mainstream methods. However, brittleness measured by the stress drop rate ignored the effect of stress drop path on brittleness index; brittleness measured through energy evolution usually neglected the effect of the length of the fracture stage on brittleness index.

The process of compressing rock to fracture is a process of energy accumulation and release. As shown in Figure 1, energy accumulated within the rock sample before peak stress can be divided into dissipated energy $\left(U_{d}\right)$ and elastic strain energy $\left(U_{e}\right)$, among which the dissipated energy is used to initiate and develop cracks, and elastic strain energy is stored within the rock. After the peak stress, additional energy is imported and accumulated to fracture rock, the total energy used for breaking rock sample is defined as $U_{f}$, and the part of strain energy stored within fractured rock sample as residual elastic energy is marked as $U_{r}$. From the perspective of strain energy, the failure of rock sample under compression is a process of elastic strain energy which accumulates and then releases; namely, a process of elastic strain energy drops. Batougina [22-24] treated the ratio of elastic strain energy drop to the fracture energy as brittleness index. Inspired by this, an indicator characterizing the elastic strain energy drop rate is proposed as a new brittleness index $\left(B_{i}\right)$; the expression is shown as follows:

$$
\begin{aligned}
B_{i} & =\frac{\mathrm{d} U}{\mathrm{~d} \varepsilon}, \\
\mathrm{d} U & =\frac{U_{e}-U_{r}}{U_{f}}, \\
\mathrm{~d} \varepsilon & =\frac{\varepsilon_{r}-\varepsilon_{p}}{\varepsilon_{r}},
\end{aligned}
$$

where $\mathrm{d} U$ is defined as elastic strain energy drop indicator, as shown in Figures 1 and 2, $U_{e}$ is elastic strain energy, $U_{r}$ is residual elastic energy, $U_{f}$ is fracture energy, $\mathrm{d} \varepsilon$ is defined as strain indicator, $\varepsilon_{r}$ is residual strain, $\varepsilon_{p}$ is stress peak strain, 


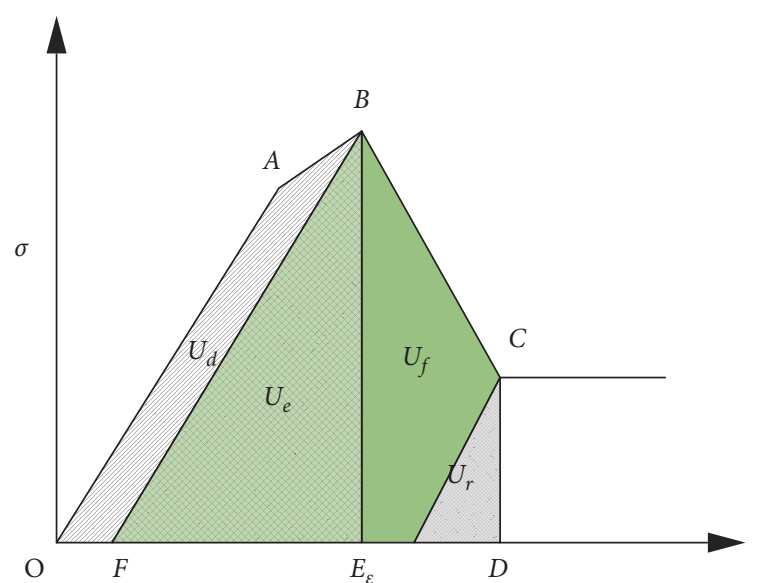

Figure 1: Strain energy evolution of rock in compression [5].

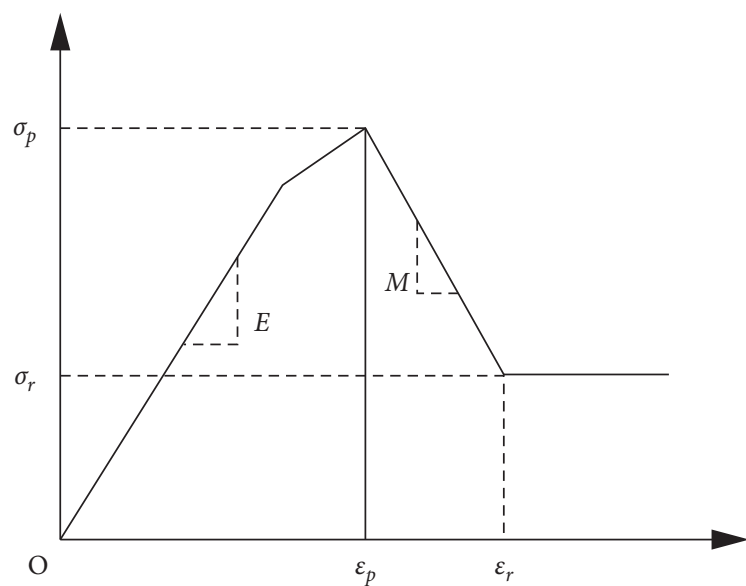

Figure 2: Scheme of representative simplified stress-strain curves [20].

and $B_{i}$ is the brittleness index. In equation (2), $U_{e}-U_{r}$ represents the released elastic strain energy during the process of rock fracturing, $\mathrm{d} U$ represents the ratio of the released elastic strain energy to fracture energy to characterize the normalized values of elastic strain energy drop. In equation (3), the value of $\varepsilon_{r}-\varepsilon_{p}$ represents the speed of rock fracturing, the smaller the value is, the faster that fracturing failure happens, and $\mathrm{d} \varepsilon$ is the normalized values of fracturing speed. $B_{i}$ represents the elastic strain energy drop rate during rock fracturing failure, whose value ranges from 0 (completely ductile) to $+\infty$ (completely brittle).

In order to simplify the calculation, the strain-stress curve is always simplified as Figure $2[5,13,20]$. Given these simplifications, the brittleness index and the related indicators are expressed as follows:

$$
\begin{aligned}
& U_{e}=\frac{\sigma_{p}^{2}}{2 E}, \\
& U_{r}=\frac{\sigma_{r}^{2}}{2 E},
\end{aligned}
$$

$$
\begin{aligned}
U_{f} & =\frac{\sigma_{p}^{2}-\sigma_{r}^{2}}{2 E}+\frac{\sigma_{p}^{2}-\sigma_{r}^{2}}{2 M}, \\
B_{i} & =\frac{M \varepsilon_{r}}{(M+E)\left(\varepsilon_{r}-\varepsilon_{p}\right)},
\end{aligned}
$$

where $\sigma_{p}$ and $\varepsilon_{p}$ are the peak stress and its corresponding strain, respectively, $\sigma_{r}$ and $\varepsilon_{r}$ are the residual stress and residual strain, respectively, $E$ is the elastic modulus, and $M$ is the absolute value of the postpeak modulus.

2.2. Verification of Brittleness Index. To verify the applicability of brittleness index $\left(B_{i}\right)$ proposed in this paper, comparison is made between $B_{i}$ and the two recently proposed recognized indices. It should be noticed that each brittleness index has its own range and some brittleness indices increase with brittle enhanced while other brittleness indices decrease with brittle enhanced. Therefore, it is of little significance to compare values of different brittleness indices even in the same condition while these brittle trends of rock samples under different conditions described by various brittleness indices can be selected as an object to verify the validity of the newly estimated brittleness index.

Figures 3 and 4 present the comparison between $B_{i}$ and $B_{1}$ [5] of three types of materials under different confining pressure. It can be found from the definition of $B_{i}$ and $B_{1}$ that both of these two brittleness indices increase with the brittleness of rock enhanced. In terms of the value of brittleness indices, even though $B_{i}$ and $B_{1}$ are not comparable as their value range is different, the degree of brittleness of different materials measured by these two indices can be compared. As can be seen from Figure 3(a), the order of the degree of brittleness among three types of samples in the evaluation system of $B_{1}$ is cement mortar, T2b marble, and granite; namely, the material becomes more brittle with the order. In the evaluation system of $B_{i}$, Figure 3(b) shows that the order of the degree of brittleness is cement mortar, T2b marble, and granite too. In terms of brittleness index change trends with confining pressure, it can be found from Figure 4 that both $B_{i}$ and $B_{1}$ decline with confining pressure increase, which indicates that brittleness of materials decline with confining pressure increase. In conclusion, $B_{i}$ is consistent with $B_{1}$ on describing the degree of brittle.

Figures 5 and 6 present the comparison between $B_{i}$ and $B_{2}$ [21] of three types of rock sample under different confining pressure. There is one thing calling for special attention that the trend of brittleness index represents inverse brittle trend in the evaluation system of $B_{i}$ and $B_{2}$. According to the definition of these indices, brittleness index $B_{i}$ increases with the brittleness of rock enhancing; on the contrary, brittleness index $B_{2}$ decreases with the brittleness of rock enhancing.

In terms of the value of brittleness indices, even though $B_{i}$ and $B_{2}$ are not comparable as their value range is different, the degrees of brittleness of different rock types measured by these two indices can be compared. As can be seen from Figure 5(a), the order of degree of brittleness among three types of rock samples in the evaluation system of $B_{2}$ is red 


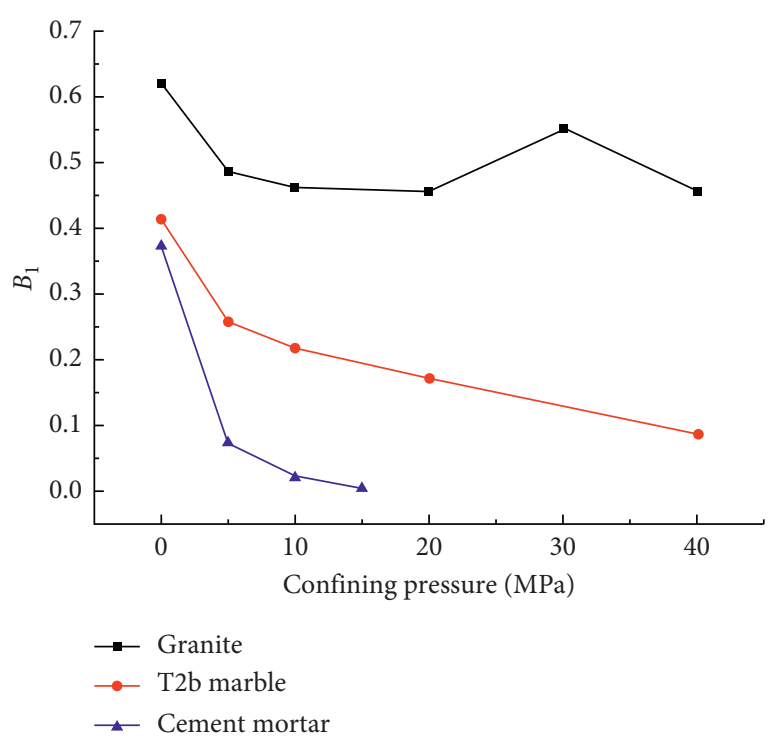

(a)

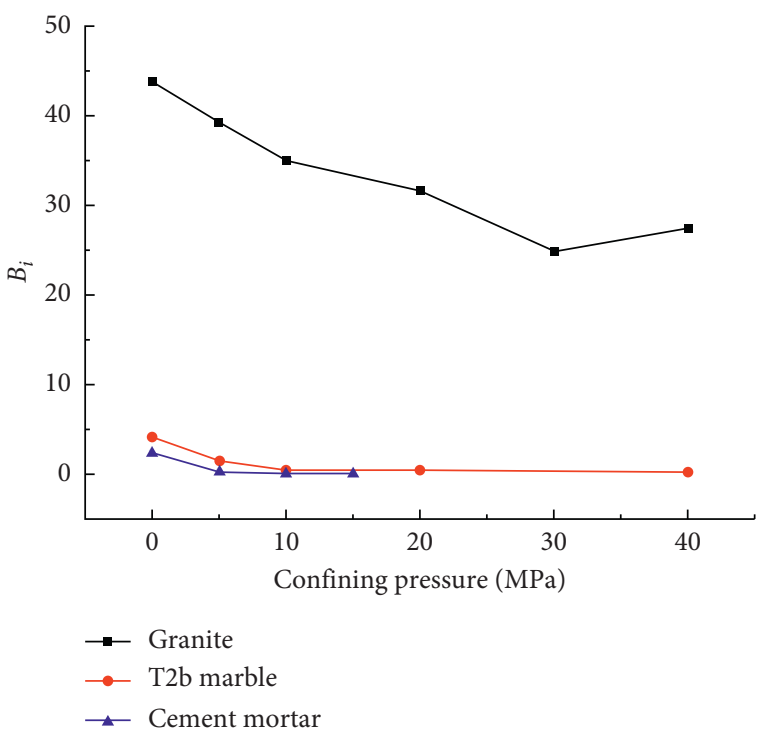

(b)

Figure 3: Brittleness order of materials under various confining pressure in different index systems: (a) $B_{1}$ and (b) $B_{i}$.

sandstone, shale, and granite, namely, rock materials become more brittle with the order. In the evaluation system of $B_{i}$, Figure 5(b) shows that the order of the degree of brittleness is red sandstone, shale, and granite too. In terms of brittleness index change with confining pressure, it can be seen from Figure 6 that $B_{i}$ declines with confining pressure increases, which indicates that all the materials show a trend of becoming less brittle with confining pressure increases. In Figure $6, B_{2}$ increases with the confining pressure increasing, which also indicates that all the materials show a trend of becoming less brittle with confining pressure increase. In conclusion, $B_{i}$ is consistent with $B_{2}$ when measuring the degree of brittleness. By comparing $B_{i}$ with the two newly proposed brittleness indices, $B_{1}$ and $B_{2}$, it is verified that $B_{i}$ is applicable for brittleness measuring.

\section{Materials and Methods}

3.1. Samples and Facilities. In order to investigate the damage and brittleness of sandstone under the effect of recurrent F-T cycles, sandstone samples were prepared. Sandstone samples used in this experiment were taken from northern Sichuan province, southwest of China, undergoing seasonal F-T cycles. Samples were medium fine and yellow in color and mainly consisted of quartz, illite, montmorillonite, and clay. They had a dry density of $2.10 \mathrm{~g} / \mathrm{cm}^{3}$, a natural moisture content of $3.08 \%$, and an initial porosity of $10.00 \%$. To ensure the consistency of the samples, all the rock samples were taken from intact and unweathered sandstone through the water drilling method. All the cylinder samples were made $50 \mathrm{~mm}$ in diameter and $100 \mathrm{~mm}$ in height suggested by ISRM.

Facilities applied in this experiment include AniMR-150 NMR imaging system, TDS-300 Freezing-Thawing test machine, and SHT4206 hydraulic servo-controlled machine. AniMR-150 NMR imaging system [25, 26], shown as
Figure 7, which was used to detect the porosity change and pore structure of the rock, was manufactured by Niumag Electric Technology Company, Ltd. in the city of Shanghai. The TDS-300 Freezing-Thawing test machine, shown as Figure 8, was manufactured by Donghua Testing Equipment Company, Ltd. in the city of Suzhou. It is an automated machine that can apply a temperature range of $-40^{\circ} \mathrm{C}$ to $+40^{\circ} \mathrm{C}$ to rock samples [27]. The SANS-SHT4206 hydraulic servo-controlled machine, shown as Figure 9, applied to the uniaxial compression test was manufactured by MTS industrial systems (China) Company, Ltd. in the city of Shanghai. It has a load capacity of $2 \mathrm{MN}$ and offers three uniaxial compression modes, namely, displacement control, load control, and strain control.

3.2. Experimental Methods. Totally, 15 samples were involved in the experiment, all the samples were divided into 5 groups corresponding to samples that suffered $0,10,20,30$, and $40 \mathrm{~F}-\mathrm{T}$ cycles, respectively, and each group had 3 samples. As pores and cracks detecting through NMR imaging system is based on the detection of water within the samples, therefore, the samples were vacuum saturated for 4 hours with vacuum pressure of $0.1 \mathrm{MPa}$ and soaked into distilled water for 24 hours to be water-saturated [25, 27]. After that, samples were placed into the NMR imaging system to measure the initial porosity and magnetic resonance images (MRI) before the F-T test. During the F-T test, all samples were placed into the Freeze-Thaw chamber and the temperature inside the F-T test machine chamber was set ranging from $-20^{\circ} \mathrm{C}$ to $+20^{\circ} \mathrm{C}$ [25-27]. As shown in Figure 10, each F-T cycle took 10 hours in total: 4 hours for freezing at temperature of $-20^{\circ} \mathrm{C}$ and 4 hours for thawing at temperature of $+20^{\circ} \mathrm{C}$ according to the "Test Methods of Rock for Highway Engineering" suggested by the Ministry of Transport of the People's Republic of China. 


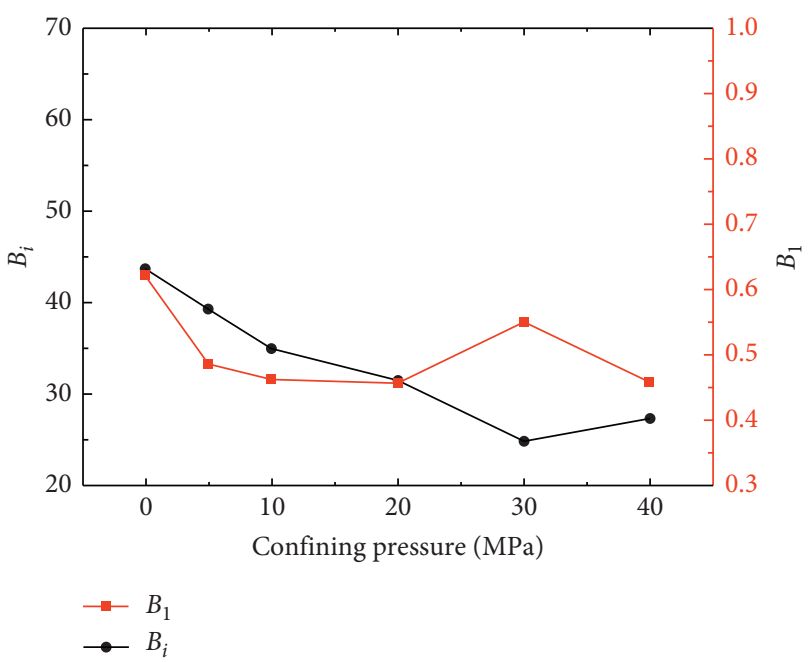

(a)

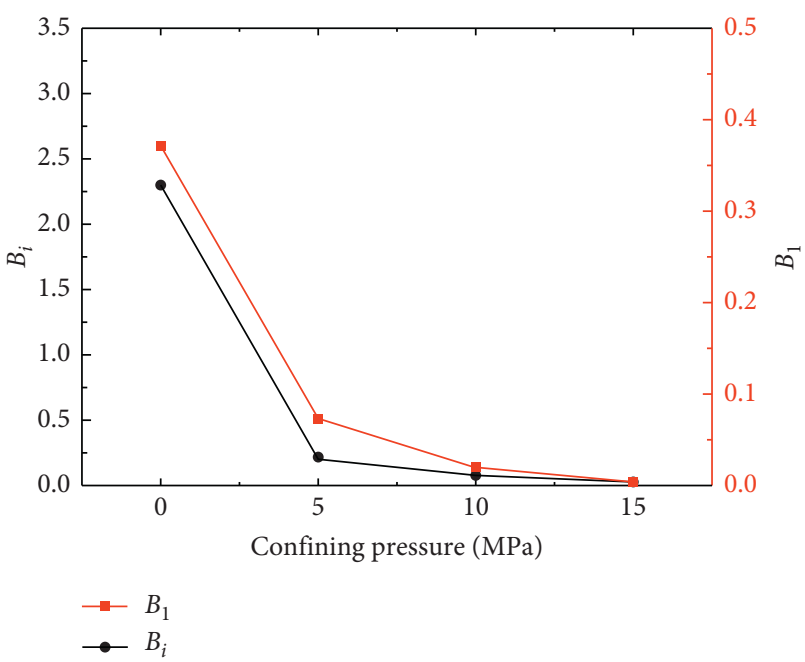

(b)

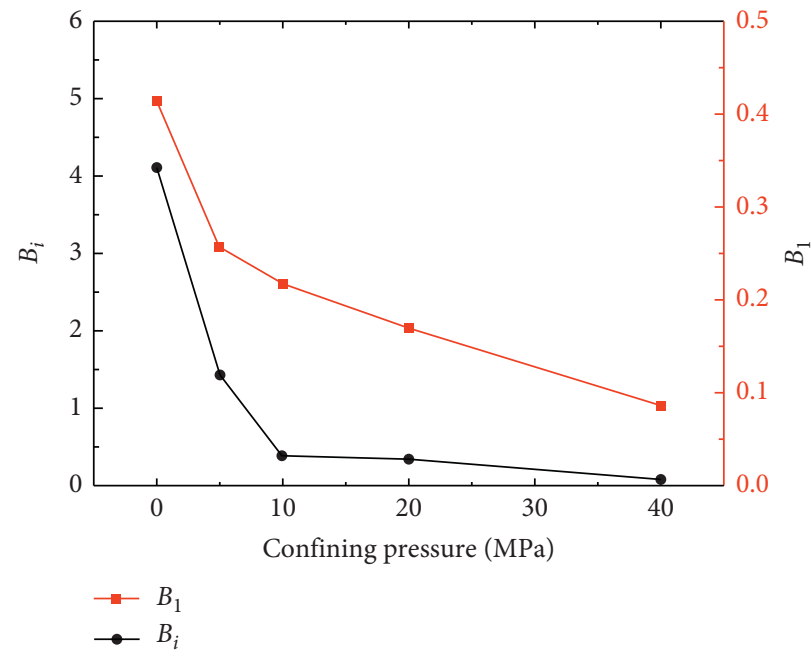

(c)

Figure 4: Variation tendency of $B_{i}$ and $B_{1}$ of various materials under different confining pressure: (a) granite, (b) cement mortar, and (c) T2b marble.

Samples were taken out of F-T test machine for NMR test after every 10 cycles until they reached the set cycles. Therefore, the NMR parameters of rock samples that suffered different F-T cycles were obtained. After the F-T test and NMR test, all the samples were subjected to the uniaxial compression test to obtain mechanical characteristics and strain-stress curves of samples. The uniaxial compression test was conducted with a computerized strain control model at a constant loading rate of $0.1 \mathrm{~mm} / \mathrm{min}$. During the loading process, the load applied to the samples was monitored by the machine and the strain of the specimen was monitored by a linear variant differential transducer.

\section{Results and Analysis}

4.1. Physical and Mechanical Parameters. Through the uniaxial compression test and NMR test, mechanical parameters and physical parameters of the samples subjected to the recurrent F-T cycles were obtained. The physical parameter measured through NMR system in this paper is porosity, characterizing the inner damage and defects of the sandstone samples. Mechanical parameters obtained through the uniaxial compression test include elastic modulus, value of the postpeak modulus, peak stain, peak stress, residual stain, and residual stress.

The porosity of sandstone samples shows a growth trend with the F-T cycles that samples underwent. Figure 11 presents that the average porosity increases dramatically from the original $10.00 \%$ to $17.05 \%$ after $40 \mathrm{~F}$-T cycles. The porosity increases in a nonlinear path. The average porosity gains an increment of $4.64 \%$ between $0 \mathrm{~F}-\mathrm{T}$ cycles and $20 \mathrm{~F}-\mathrm{T}$ cycles while getting an increment of $2.41 \%$ between $20 \mathrm{~F}-\mathrm{T}$ cycles and $40 \mathrm{~F}-\mathrm{T}$ cycles. It means that the growth rate of porosity slows down with F-T cycles.

In terms of variation of mechanical parameters, Figure 12 and Table 1 give an intuitive and detailed presentation, respectively. Among these mechanical parameters, elastic modulus, value of the postpeak modulus, 


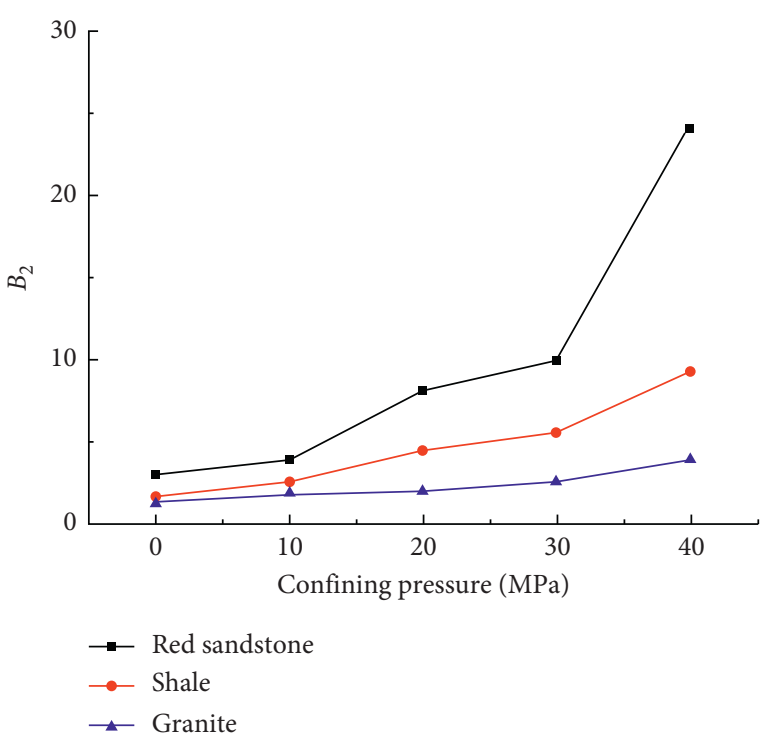

(a)

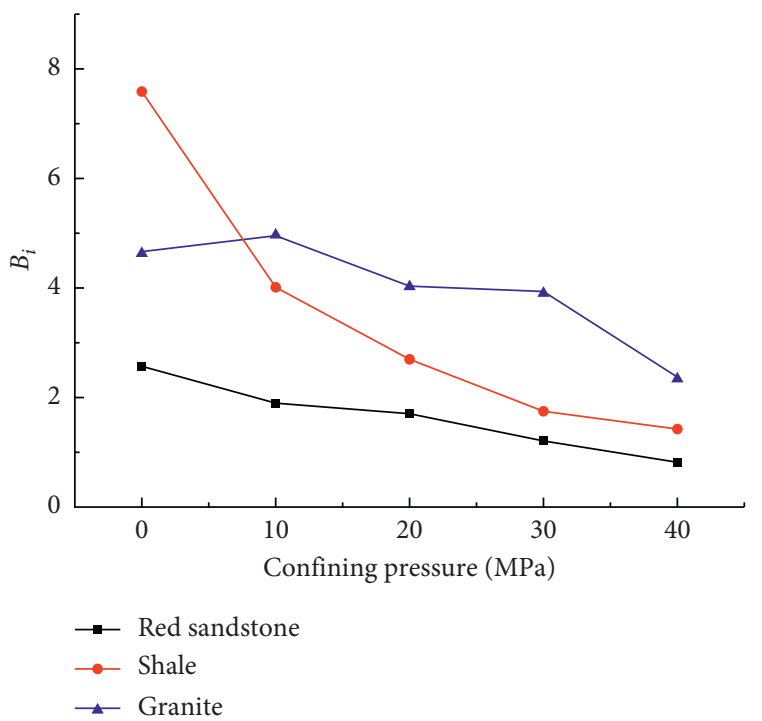

(b)

Figure 5: Brittleness order of the materials under different confining pressure in different index systems: (a) $B_{2}$ and (b) $B_{i}$.

and peak stress show the apparent change rule while peak stain, residual stain, and residual stress are disorder. Figure 12 presents typical strain-stress curves of the sandstone subjected to different F-T cycles. It can be seen intuitively from Figure 12 that the mechanical characteristics including elastic modulus and peak stress decrease with F-T cycles adding up. As can be seen from Table 1, elastic modulus of the samples treated by $0,10,20$, 30 , and $40 \mathrm{~F}-\mathrm{T}$ cycles are $10.82,10.36,5.56,2.14$, and $0.92 \mathrm{GPa}$, respectively. It reveals that the recurrent F-T weathering worsens the elasticity of sandstone dramatically. Peak stress is also sensitive to F-T weathering. Peak stress of the samples treated by $0,10,20,30$, and $40 \mathrm{~F}-\mathrm{T}$ cycles are $31.805,27.323,18.678,7.795$, and $3.608 \mathrm{MPa}$, which means that F-T weathering also deteriorated the carrying capacity of samples. The value of the postpeak modulus is a parameter characterizing the brittleness according to the previous studies. It shows a decrease trend with F-T cycles adding up, with an original value of 117.241 GPa sharply decreasing to $2.415 \mathrm{GPa}$ after $40 \mathrm{~F}-\mathrm{T}$ cycles. Combining the postpeak characteristic shown in Figure 12, the variation trend of the value of the postpeak modulus indicates that brittleness of sandstone decreases when F-T cycles increase.

Among these parameters, the elastic modulus, the value of the postpeak modulus, and the peak stress decline with the F-T cycles increase, which indicates the degradation of rock mechanical properties. Porosity increasing with F-T cycles shows the pores and cracks generated, developed, and accumulated in rock samples, which indicates the degradation of rock physical property and causes the degradation of mechanical parameters. Overall, the physical and mechanical characteristics analyzed in this paper worsen with F-T cycles.
4.2. Magnetic Resonance Images (MRI). Magnetic resonance images (MRI) of the sandstone under different F-T cycles are shown in Figure 13. In MRI, light spots represent water in sample [28], namely, pores in sample. The bigger and the lighter these spots, the lager these pores. As can be seen from Figure 13, light spots inside the sandstone increase with F-T cycles increase, which means that the pores inside the sandstone increase with the F-T cycles going on.

It is worth noting that the initial sandstone that has not suffered F-T cycles is dark overall; spots are concentrated on the surface of the sandstone. After $10 \mathrm{~F}-\mathrm{T}$ cycles, spots become more inside the sandstone, and they become lighter and go deeper from the surface. When the F-T cycles come to 20 , more spots occur inside the sandstone. After $30 \mathrm{~F}-\mathrm{T}$ cycles, spots are becoming lighter than before, especially around the surface of sample, and even surface appears to peel off. When it comes to 40 cycles, spots are full of sandstone; compared with the initial state, spots gain great incensement in both quantity and size. Spots around the surface of the sandstone even developed into ribbons, indicating that $\mathrm{F}-\mathrm{T}$ weathering augmented pores in both quantity and size, and some cracks occur in the sandstone.

Overall, the microstructures become developed with F-T cycles increase. These developed microstructures would degrade the bearing capacity of the sandstone and enhance the deformation ability of the sandstone when loading. The storage energy capacity of sandstone becomes worse with F-T cycles increase. Therefore, sandstone also gradually changed from brittleness to ductility.

4.3. Brittleness Index. The brittleness index $B_{i}$ derived from equation (5) proposed in this paper is positively related to the brittleness degree of the material, which means that $B_{i}$ 


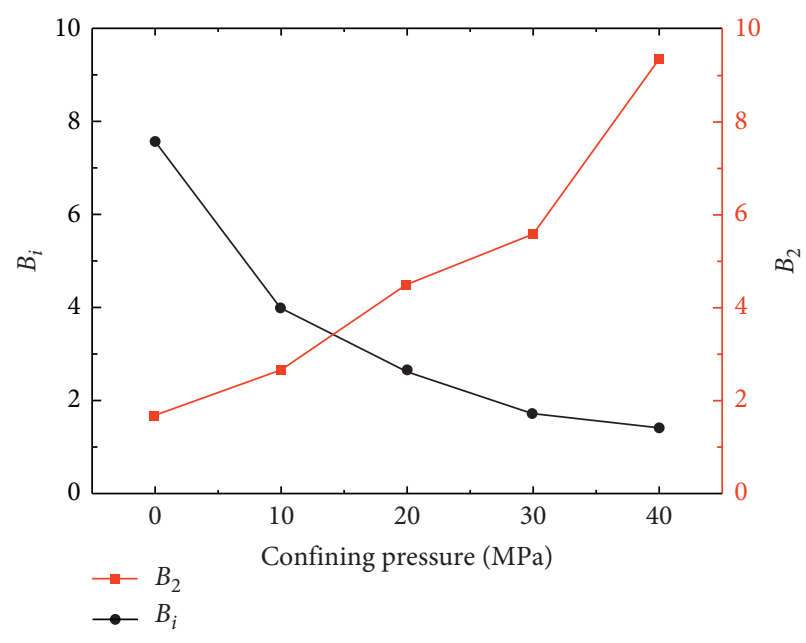

(a)

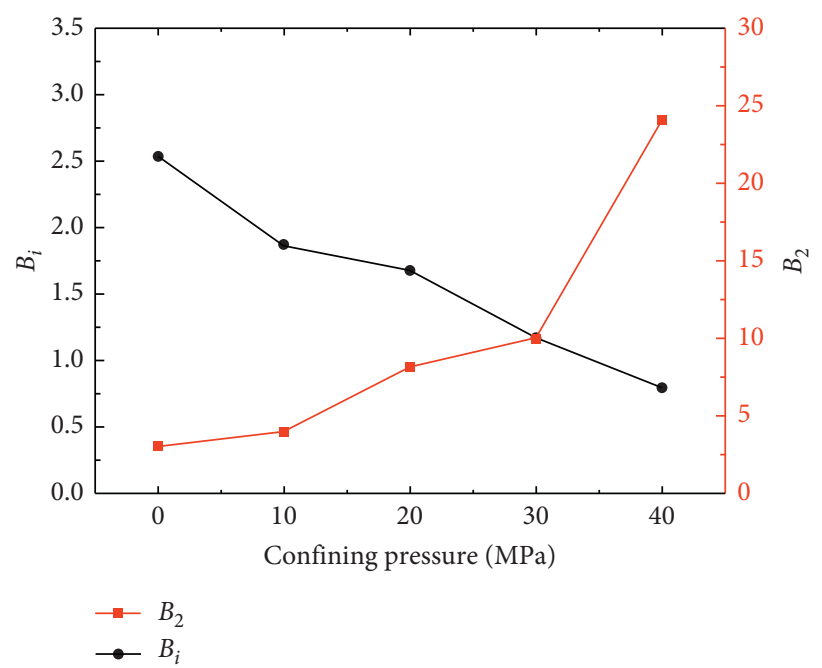

(b)

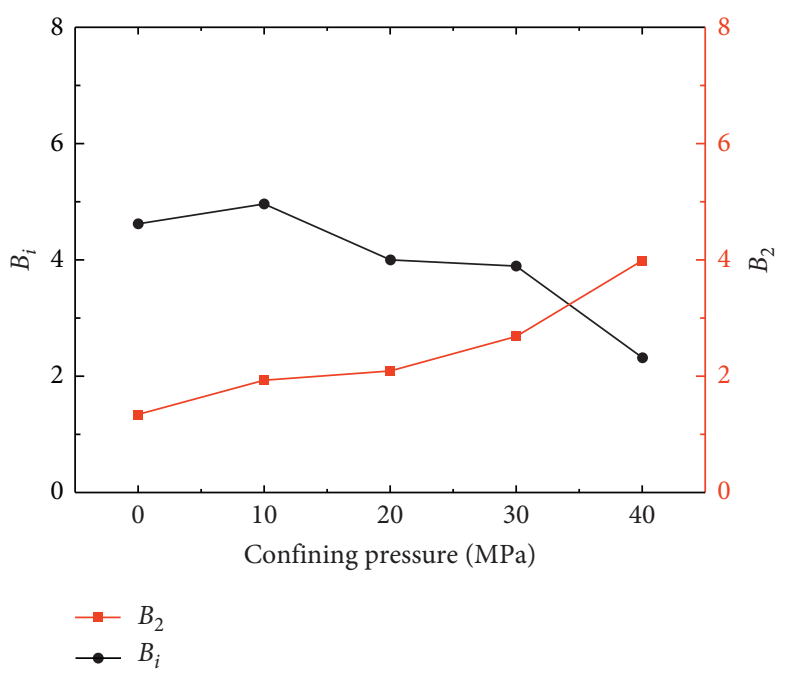

(c)

Figure 6: Variation tendency of $B_{i}$ and $B_{2}$ of various samples under different confining pressure: (a) shale, (b) red sandstone, and (c) granite.

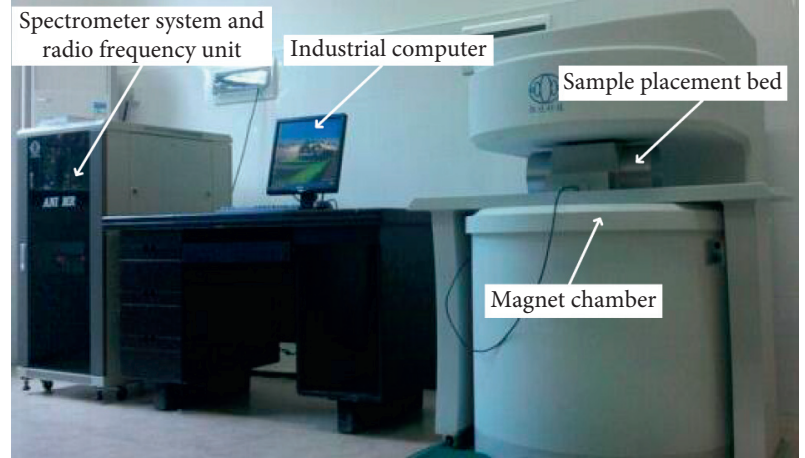

Figure 7: AniMR-150 NMR imaging system.

increase with the enhancement of the brittleness of the rock. Based on equation (5) and the parameters obtained from the compression test, the brittleness of the sandstone samples treated with different F-T cycles was calculated and listed in

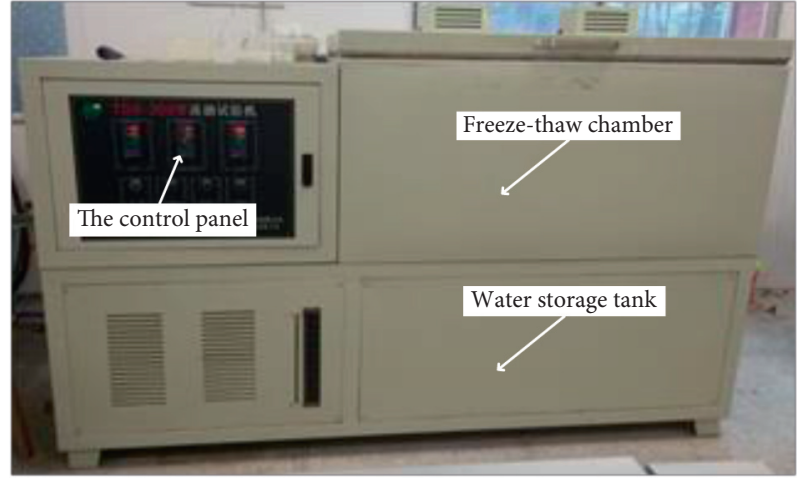

Figure 8: TDS-300 F-T test machine.

Table 1 . And the relationships between the brittleness and mechanical parameters and porosity are drawn in Figure 14.

Figure 14 reveals the correlation between the brittleness indices and the various parameters. As shown in 


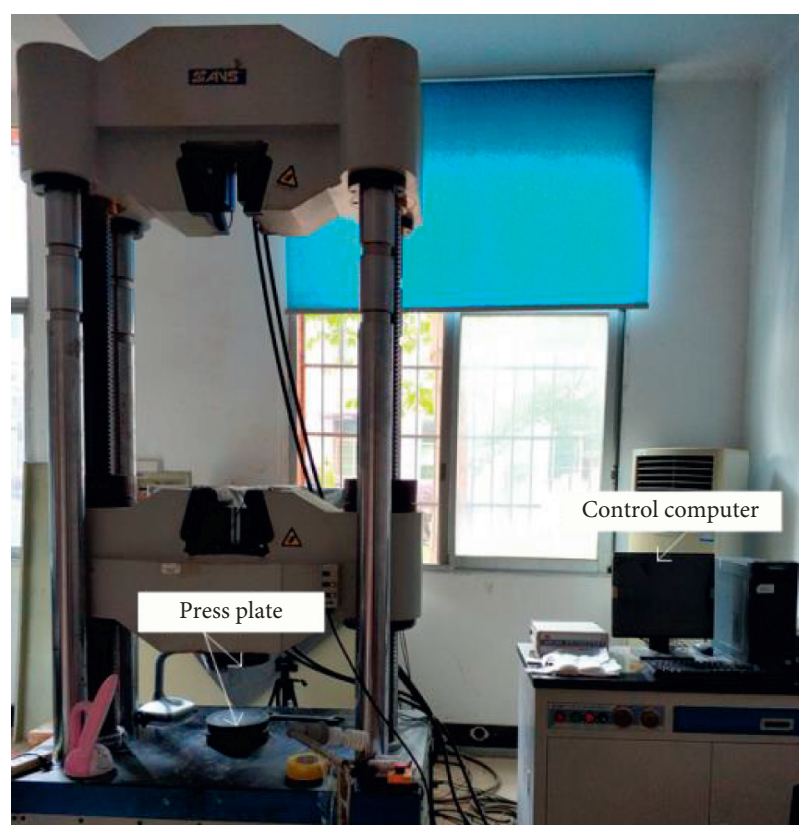

FIgURE 9: SANS-SHT4206 hydraulic servo-controlled machine.

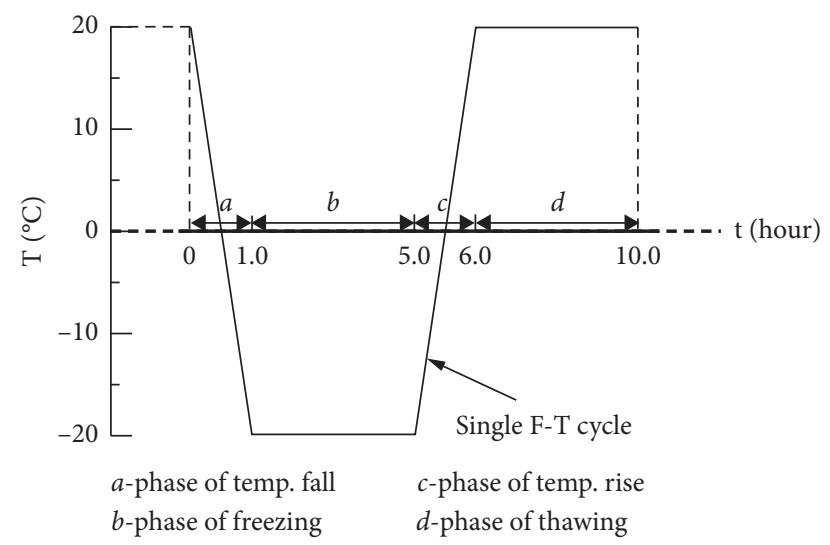

Figure 10: Temperature schematic diagram of F-T tests in a single cycle.

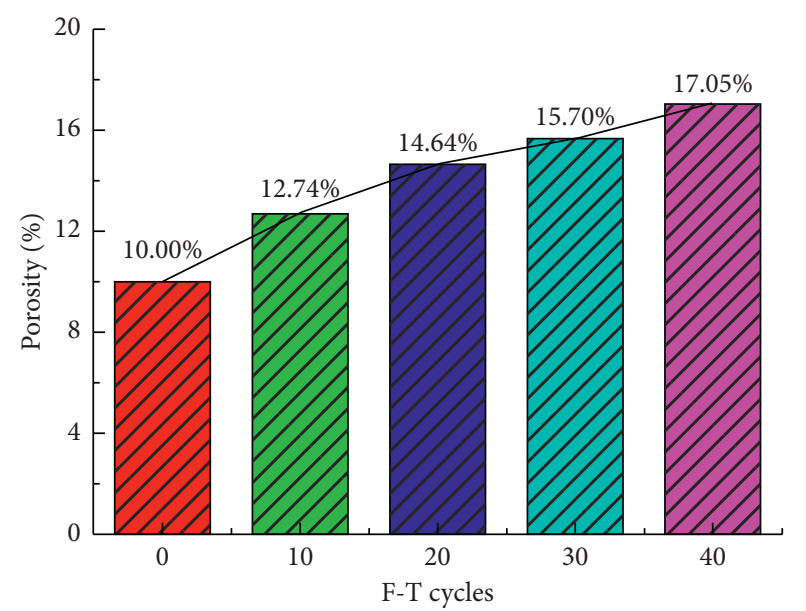

FIGURE 11: The trend of the average porosity varies with F-T cycles.
Figure 14(a), it displays that the brittleness index shows a decline trend with F-T cycles increase, which reveals that the brittleness degree of sandstone decreases with the F-T cycles increase. Also, it can be seen from Figure 14(a) that the proposed brittleness index declines with F-T cycles exponentially, which means the brittleness of sandstone drops rapidly at the beginning of $\mathrm{F}-\mathrm{T}$ weathering while the brittleness of sandstone declines slowly when F-T cycles reach 20. Similar to Figure 14(a), Figure 14(c) presents a trend that the proposed brittleness index declines with sandstone's porosity exponentially. Figures 14(b) and 14(d) show that the proposed brittleness index grows with stress peak and elastic modulus increase.

It can be found from Figure 14 that $20 \mathrm{~F}-\mathrm{T}$ cycles is a threshold point of brittleness. When F-T cycles is less than 20 , the brittleness index drops fast and dramatically. When F-T cycles is more than 20, the brittleness index decreases slowly. This phenomenon can also be found in Figure 12. It can be seen from Figure 12 that the elastic strain energy stored in sandstone samples that suffered less than $20 \mathrm{~F}-\mathrm{T}$ cycles is much greater than those samples that suffered more than $20 \mathrm{~F}-\mathrm{T}$ cycles. In the meantime, those sandstone samples suffered less than $20 \mathrm{~F}$-T cycles ruptured with slight strain beyond the yield stress while sandstone samples suffered more than $20 \mathrm{~F}$-T cycles ruptured with much more strain beyond the yield stress. Therefore, $20 \mathrm{~F}-\mathrm{T}$ cycles are a turning point for the brittleness of sandstone in this experiment. Furthermore, the above results show that the brittleness index proposed in this paper is well correlated with F-T cycles, peak stress, porosity, and elastic modulus, which indicates that the proposed brittleness index is suitable for brittle evaluation.

4.4. Discussion. The degradation of the mechanical properties and brittleness of sandstone which suffered recurrent F-T cycles result from the destruction of internal structure. The increase of internal damage is indicated by the increase of sandstone's porosity. During the process of F-T test, the increase of sandstone's porosity is caused by two means. One is that the dissolution of soluble components promotes the growth of the porosity. As the sandstone adapted in this test consisted of quartz, illite, montmorillonite, and clay, clay was dissolved in water during the process of F-T test. Another reason is that the ice crystallization pressure $[27,29]$ and migration of unfrozen water [30] in rock caused damage to sandstone in the process of F-T test. In the recurrent F-T cycles, $9 \%$ of the volume growth of water during the freezing phase casted crystallization pressure on rock; once the crystallization pressure exceed the tensile strength of rock, new pores and damage were generated. In both phases of freezing and thawing, the migration of unfrozen water that drove by capillary and osmotic pressure also damaged rock sample. Therefore, porosity and defects increment caused by F-T weathering not only degraded the mechanical property of sandstone, but also turned transformed sandstone from brittleness to ductility.

Porosity reflects the overall pore volume and damage inside the samples, and T2 spectrum characterizes the 


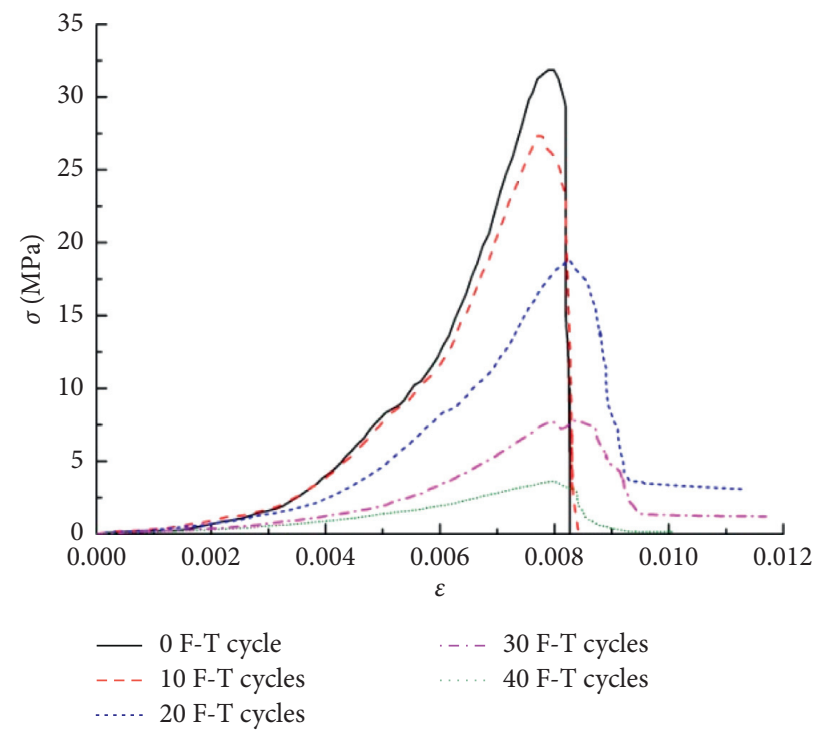

FIgURE 12: Typical strain-stress curves of sandstone underwent various F-T cycles.

TABLE 1: Mechanical parameters, porosity, and brittleness index values of the samples subjected to various F-T cycles.

\begin{tabular}{lcccccccc}
\hline F-T cycles & $E(\mathrm{GPa})$ & $M(\mathrm{GPa})$ & $\varepsilon_{p}\left(10^{-3}\right)$ & $\varepsilon_{r}\left(10^{-3}\right)$ & $\sigma_{p}(\mathrm{MPa})$ & $\sigma_{r}(\mathrm{MPa})$ & Porosity $(\%)$ \\
\hline 0 & 10.820 & 117.241 & 7.995 & 8.266 & 31.805 & 0.000 & 10.00 & 27.896 \\
10 & 10.360 & 42.969 & 7.777 & 8.413 & 27.323 & 0.000 & 12.74 \\
20 & 5.560 & 12.957 & 8.270 & 9.382 & 18.678 & 4.140 & 10.660 \\
30 & 2.140 & 5.239 & 8.412 & 9.700 & 7.795 & 1.382 & 14.64 \\
40 & 0.920 & 2.415 & 8.006 & 9.500 & 3.608 & 0.156 & 15.70 \\
\end{tabular}

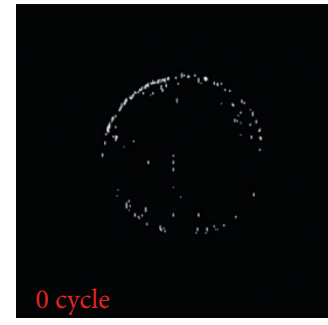

(a)

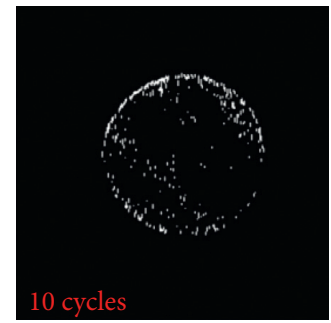

(b)

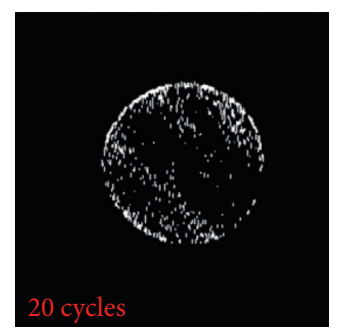

(c)

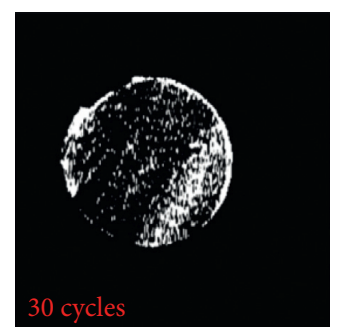

(d)

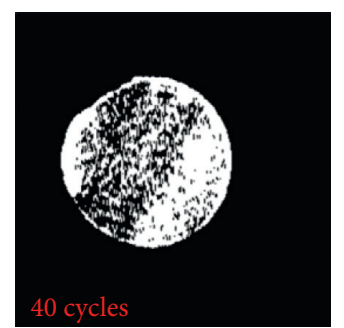

(e)

FIgURE 13: Evaluation of the microstructure inside the sandstone after various F-T cycles in view of MRI.

distribution of pore size and pore number inside the samples $[26,27]$. In terms of pore structure of sandstone which suffered various F-T cycles, the authors had done this analysis in [27] before, and the T2 spectrum of sandstone which suffered different F-T cycles is shown in Figure 15.
In Figure 15, T2 is positively correlated with pore size; the porosity component represents the proportion of certain pore size, and the area covered by $\mathrm{T} 2$ spectrum curve represents the porosity of samples. Figure 15 shows that T2 spectrums have two peaks: the left peak represents micropores and the 


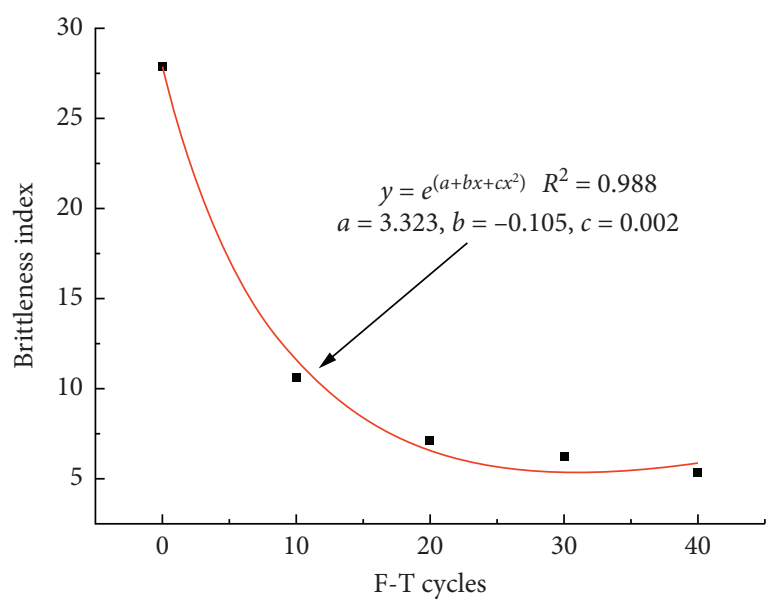

- Experiment data _ Fitting line

(a)

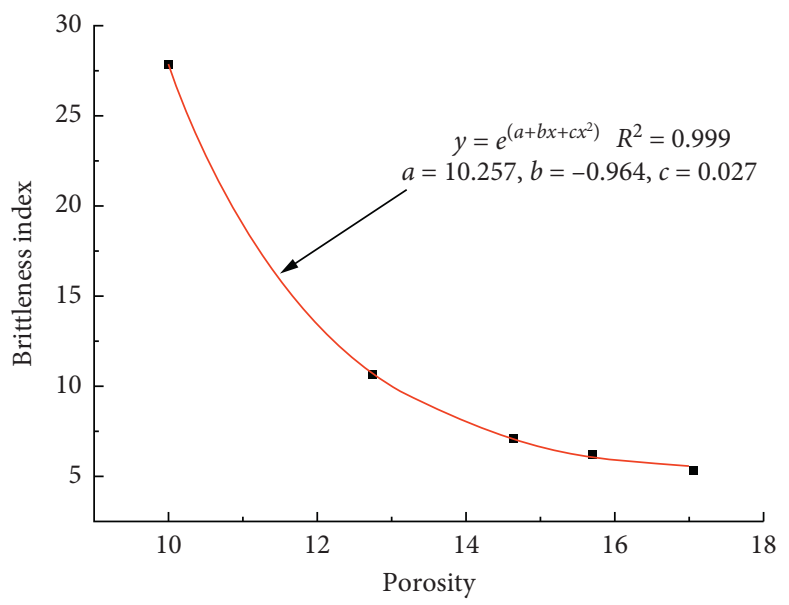

- Experiment data

Fitting line

(c)

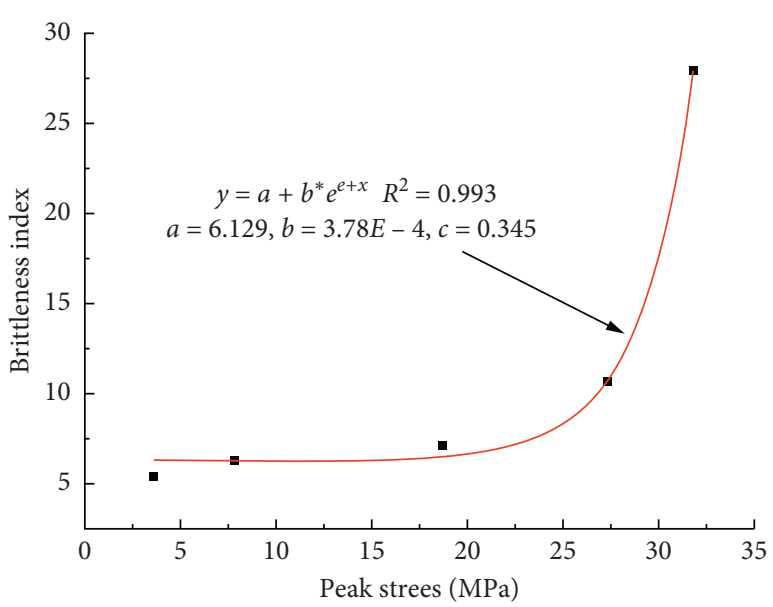

- Experiment data

_ Fitting line

(b)

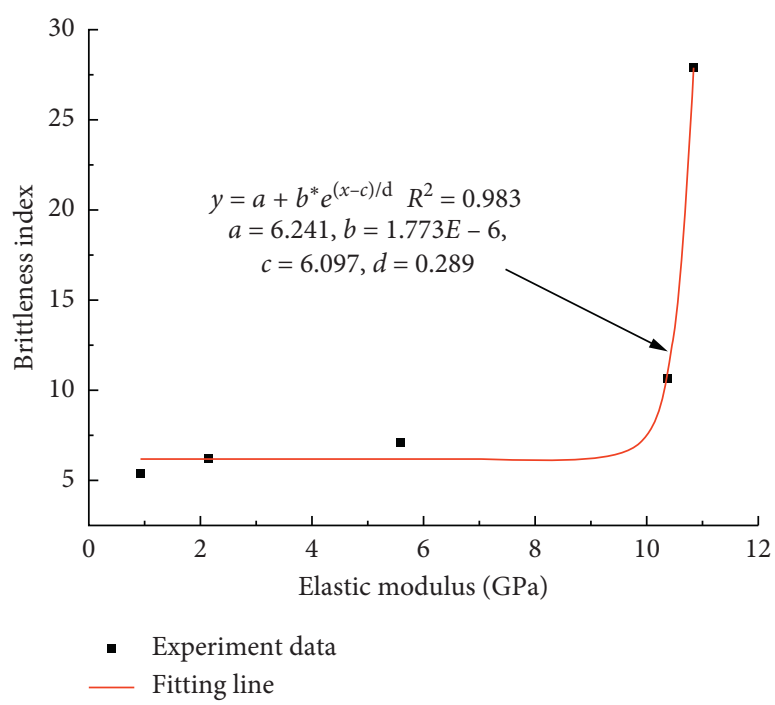

(d)

FIGURE 14: Correlation between the brittleness indices and (a) F-T cycles, (b) peak stress, (c) porosity, and (d) elastic modulus.

right peak represents macropores. Figure 15 reveals that the porosity of sandstone increases with F-T cycles exerted on the sandstone, which is consistent with Figure 11. When the F-T cycles is smaller than 20 , both the pore size and pore number increased with F-T cycles, which indicates new pores continuously generated and primary pores expanded to a larger size in this phase. When the F-T cycles are larger than 20, macropores developed rapidly, which means it is a phase of pore expanding and penetrating. With the F-T cycles applied to the sandstone increasing, pores and cracks accumulated inside sandstone, leading to the increase of internal damage and nonuniformity and the decrease of the effective bearing area. Therefore, mechanical parameters including elastic modulus, peak stress, and the value of the postpeak modulus decreased and its brittleness weakened.
Additionally, as F-T weathering decreases the cohesion and strain energy storage capacity by damaging the structure of sandstone, the residual strain shows a trend of increasing with F-T cycles. Therefore, brittleness decreases with the increase of the F-T cycles according to the proposed brittleness index. Brittleness changes of the sandstone that suffered different $\mathrm{F}-\mathrm{T}$ cycles can also be revealed by their failure morphology. The failure morphology of the sandstone that suffered different $\mathrm{F}-\mathrm{T}$ cycles in the uniaxial compression test is shown in Figure 16. For sandstone that did not suffer F-T cycles, it shows shear failure and generates many rock pieces of different sizes, which are signs of brittleness. For sandstone that suffered $40 \mathrm{~F}-\mathrm{T}$ cycles, the failure pattern of sandstone turns to tensile failure, and few rock pieces are generated, which are signs of ductility. 20 F-T cycles are an obvious turning point of sandstone's 


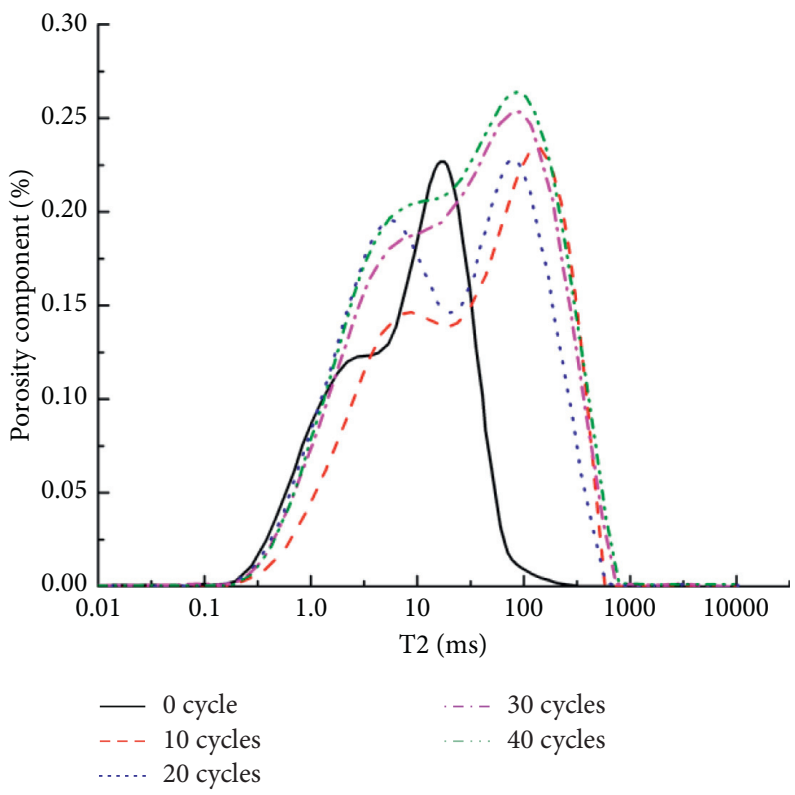

FIGURE 15: T2 spectrum of sandstone that suffered different F-T cycles [27].

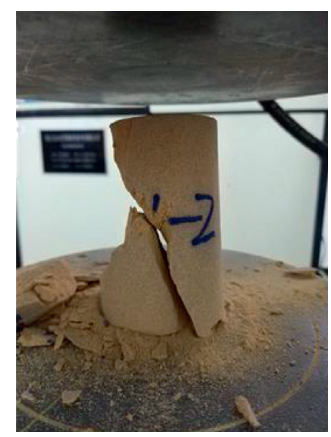

0 cycle

(a)

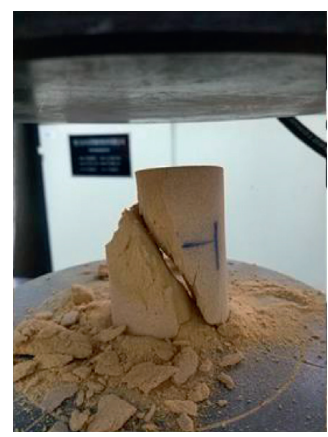

10 cycles

(b)

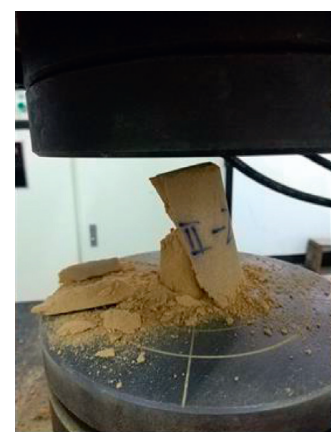

20 cycles

(c)

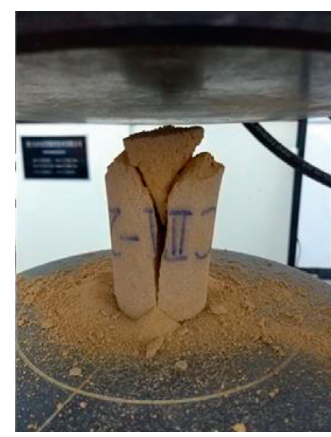

30 cycles

(d)

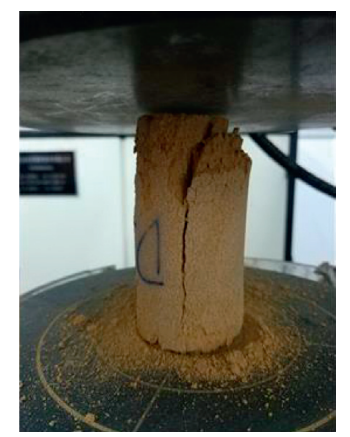

40 cycles

(e)

FIGURE 16: Failure pattern of the sandstone that suffered different F-T cycles in the uniaxial compression test.

brittleness. From the perspective of the failure pattern, the failure pattern of sandstone changes from shear failure to tensile failure at $20 \mathrm{~F}-\mathrm{T}$ cycles, which indicates that $20 \mathrm{~F}-\mathrm{T}$ cycles are a turning point of rock brittleness, and the samples change from obvious brittle to ductile.

\section{Conclusions}

Brittleness is a property of quite importance in rock mass evaluation. In this study, an energy release rate based brittleness index is proposed and verified; then, it was used to evaluate the brittleness of sandstone subjected to various F-T cycles, and mechanical characteristics and microstructure are also analyzed. Conclusions drawn from this study are as follows.

(a) In this study, the concept of elastic strain energy release rate is proposed, and an elastic strain energy release rate based brittleness index $B_{i}$ for rock material is proposed and then verified with two recently proposed brittleness indices. (b) Elastic modulus, the value of the postpeak modulus, and the peak stress decline with F-T cycles increases, while the porosity growth with F-T cycles increases, and the MRI is used to reveal the evolution of microstructure sandstone after F-T cycles.

(c) The proposed brittleness index is well correlated with F-T cycles, stress peak, porosity, and elastic modulus. It declines exponentially with F-T cycles and porosity increase while growing exponentially with peak stress and elastic modulus increase, and $20 \mathrm{~F}-\mathrm{T}$ cycles are a turning point for brittleness of sandstone in this study.

\section{Data Availability}

The data used to support the findings of this study are available from the corresponding author upon request.

\section{Conflicts of Interest}

The authors declare no conflicts of interest. 


\section{Authors' Contributions}

S. Y. and H. D. designed and conducted the experiment and analyzed data of this paper; S. Y. and J. D. proposed the brittleness index in this paper and they wrote the manuscript of this paper; and S. Y and J. D. helped to draw the figures and improve the manuscript in language and grammar.

\section{Acknowledgments}

The authors thank Yanan Zhang for his help in data analysis and thank Zhen Jian for his support in conducting the experiment. This research was funded by National Natural Science Foundation of China (Grant no. 51874352) and Natural Science Foundation of Hunan Province (Grant nos. 2020JJ4704 and 2020JJ4712).

\section{References}

[1] F. Mustafa and I. Ismail, "Effects of the freeze-thaw (F-T) cycle on the andesitic rocks (sille-konya/Turkey) used in construction building," Journal of African Earth Sciences, vol. 109, pp. 96-106, 2015.

[2] M. Ganesh, D. Savka, and N. Erling, "Experimental study on debonding of shotcrete with acoustic emission during freezing and thawing cycle," Cold Regions Science \& Technology, vol. 111, pp. 1-12, 2015.

[3] N. Matsuoka and H. Sakai, "Rock fall activity from an alpine cliff during thawing periods," Geomorphology, vol. 28, no. 3-4, pp. 309-328, 1999.

[4] V. Hucka and B. Das, "Brittleness determination of rocks by different methods," International Journal of Rock Mechanics and Mining Sciences \& Geomechanics Abstracts, vol. 11, no. 10, pp. 389-392, 1974.

[5] F. Meng, H. Zhou, C. Zhang, R. Xu, and J. Lu, "Evaluation methodology of brittleness of rock based on post-peak stressstrain curves," Rock Mechanics and Rock Engineering, vol. 48, no. 5, pp. 1787-1805, 2015.

[6] D. F. Coates and R. C. Parsons, "Experimental criteria for classification of rock substances," International Journal of Rock Mechanics and Mining Sciences \& Geomechanics Abstracts, vol. 3, no. 3, pp. 181-189, 1966.

[7] C. He, S. Okubo, and Y. Nishimatsu, "A study of the class II behaviour of rock," Rock Mechanics and Rock Engineering, vol. 23, no. 4, pp. 261-273, 1990.

[8] V. H. Dolmajid and P. Kaiser, "Brittleness of rock and stability assessment in hard rock tunneling," Tunnelling and Underground Space Technology, vol. 18, no. 1, pp. 35-48, 2003.

[9] G. E. Andreev, Brittle Failure of Rock Materials, CRC Press, Boca Raton, FL, USA, 1995.

[10] Q. Li, M. Chen, Y. Jin et al., "Indoor evaluation method for shale brittleness and improvement," Chinese Journal of Rock Mechanics \& Engineering, vol. 31, no. 8, pp. 1680-1685, 2012.

[11] R. Altindag, "Correlation of specific energy with rock brittleness concepts on rock cuttings," Journal of the Southern African Institute of Mining and Metallurgy.vol. 103, no. 3, pp. 163-172, 2003.

[12] A. Bishop, "Progressive failure with special reference to the mechanism causing it," in Proceedings of the Geotechnical Conference, pp. 142-150, Oslo, Norway, 1967.

[13] Y. J. Xia, L. C. Li, C. A. Tang, X. Y. Li, S. Ma, and M. Li, “A new method to evaluate rock mass brittleness based on stress- strain curves of class I," Rock Mechanics and Rock Engineering, vol. 50, no. 5, pp. 1123-1139, 2017.

[14] J. Zhang, C. Ai, Y.-W. Li, M.-G. Che, R. Gao, and J. Zeng, "Energybased brittleness index and acoustic emission characteristics of anisotropic coal under triaxial stress condition," Rock Mechanics and Rock Engineering, vol. 51, no. 11, pp. 3343-3360, 2018.

[15] Y. Li, M. Long, L. Zuo, W. Li, and W. Zhao, "Brittleness evaluation of coal based on statistical damage and energy evolution theory," Journal of Petroleum Science and Engineering, vol. 172, no. 1, pp. 753-763, 2019.

[16] Y. Li, D. Jia, Z. Rui, J. Peng, C. Fu, and J. Zhang, "Evaluation method of rock brittleness based on statistical constitutive relations for rock damage," Journal of Petroleum Science and Engineering, vol. 153, no. 5, pp. 123-132, 2017.

[17] Q. Meng, M. Zhang, L. Han et al., "Effects of acoustic emission and energy evolution of rock specimens under the uniaxial cyclic loading and unloading compression," Rock Mech Rock Eng, vol. 49, no. 10, pp. 3873-3886, 2018.

[18] Y. Liu, F. Dai, L. Dong et al., "Experimental investigation on the fatigue mechanical properties of intermittently jointed rock models under cyclic uniaxial compression with different loading parameters," Rock Mechanics and Rock Engineering, vol. 51, pp. 47-68, 2016.

[19] H. Munoz, A. Taheri, and E. K. Chanda, "Fracture energybased brittleness index development and brittleness quantification by pre-peak strength parameters in rock uniaxial compression," Rock Mechanics and Rock Engineering, vol. 49, no. 12, pp. 4587-4606, 2016.

[20] B. G. Tarasov and Y. Potvin, "Absolute, relative and intrinsic rock brittleness at compression," Mining Technology, vol. 121, no. 4, pp. 218-225, 2013.

[21] J. Zhang, C. Ai, Y. Li et al., "Brittleness evaluation index based on energy variation in the whole process of rock failure," Chinese Journal of Rock Mechanics and Engineering, vol. 36, no. 6, pp. 1326-1340, 2017.

[22] I. Batougina, Methodological Instructions for Rock Burst Prophylaxis Accounting the Deposit Geodynamics, Molochnoy Promyshlennosti Vnii, Leningrad, Russia, 1983.

[23] B. Manjikov, Laboratory Estimation of Rock Bursting Danger, pp. 106-116, Frunze, Bishkek, Kyrgyzstan, 1983.

[24] A. Stavroguin and A. Protossenia, Rock Strength and Excavation Stability in Great Depth, Nedra, Moscow, Russia, 1985.

[25] J.-L. Li, K.-P. Zhou, W.-J. Liu, and H.-W. Deng, "NMR research on deterioration characteristics of microscopic structure of sandstones in freeze-thaw cycles," Transactions of Nonferrous Metals Society of China, vol. 26, no. 11, pp. 2997-3003, 2016.

[26] H. W. Deng, C. F. Dong, J. L. Li et al., "Experimental study on sandstone freezing-thawing damage properties under condition of water chemistry," Applied Mechanics and Materials, vol. 608-609, pp. 726-731, 2014.

[27] H. Deng, S. Yu, and J. Deng, "Damage characteristics of sandstone subjected to coupled effect of freezing-thawing cycles and acid environment," Advances in Civil Engineering, vol. 2018, Article ID 3560780, 10 pages, 2018.

[28] C. Liu, H. Deng, Y. Wang et al., “Time-varying characteristics of granite microstructures after cyclic dynamic disturbance using nuclear magnetic resonance," Crystals, vol. 7, pp. 1-10, 2017.

[29] D. K. Tim, A. B. Marijn, D. S. Thomas et al., "A pore-scale study of fracture dynamics in rock using $\mathrm{X}$-ray micro ct under ambient freeze-thaw cycling," Environmental Science \& Technology, vol. 49, pp. 2867-2874, 2015.

[30] W. Charlotte, E. Javad, L. Anne et al., "Evolution of the mechanical behavior of limestone subjected to freeze-thaw cycles," Environmental Earth Sciences, vol. 74, pp. 6339-6351, 2015. 